\title{
Correction to: An IOT Based Smart Shopping Cart for Smart Shopping
}

\author{
Srinidhi Karjol (D), Anusha K. Holla (D), C. B. Abhilash (D, \\ P. V. Amrutha, and Y. V. Manohar
}

\section{Correction to: \\ Chapter "An IOT Based Smart Shopping Cart for Smart Shopping" in: T. N. Nagabhushan et al. (Eds.): \\ Cognitive Computing and Information Processing, CCIS 801, https://doi.org/10.1007/978-981-10-9059-2_33}

In the originally published chapter 33 the names of two authors who contributed to the work were not included. P. V. Amrutha and Y. V. Manohar have been added as co-authors of the paper. 